\title{
Transportation towards Tourism Sustainability: Case Study of Lebanon
}

\author{
By Viana Hassan ${ }^{*}$, Georges Bellos ${ }^{ \pm} \&$ Ranine Fawaz,
}

Sustainable tourism considers economic, social, and environmental impacts, addressing the needs of visitors, the industry, the environment, and host communities. Additionally, sustainable tourism development requires the informed participation of all relevant stakeholders and strong political leadership to ensure participation and consensus building. Nevertheless, maintaining sustainable tourism is necessary to encourage a high level of tourist satisfaction and to be able to ensure a new experience for them, while raising their awareness and promoting sustainable tourism practices. This research aims to study the sustainability of transportation in Lebanon in its broadest scope. This will be done by exploring the problems and solutions that can improve the transportation sector. Due to the lack of sustainable transportation, this research could help fill gaps to improve Lebanon's transportation sector. The study relied on qualitative method, through the utilization of Questionnaires for both residents and visitors and an expert in the field targeted through an Interview. The main findings presented in this paper have shown problems and solutions to Lebanon's transportation sector and the relation between transportation and tourism sustainability.

Keywords: sustainability, transportation, tourism, Lebanon

\section{Introduction}

Transportation is the most basic human need. It is the act of moving something from one place to another (Bougdah et al. 2017). Also, the transport sector covers different modes such as; road transport, railway, waterway, and air transport. According to the Global Facilitation Partnership (GFP) for Transportation and Trade, more than $80 \%$ of the world trade is carried by sea, constituting by far the most important means of transport of goods (Vince 2003). However, in 1841, Thomas Cook realized the first organized travel using a train, with a steam power engine. From that time, transportation became an inseparable part of tourism.

According to the UNWTO (2017), sustainable tourism takes into account economic, social, and environmental impacts, addressing all stakeholders in a particular destination.

Yet, the World Tourism Organization (2004) and Mammadov (2012) agree with the above, since maintaining sustainable tourism is necessary to encourage a high level of tourist satisfaction and to be able to ensure a new experience for them, as transportation is an integral part of this sector.

\footnotetext{
*Lecturer, Lebanese University, Lebanon and Visiting Lecturer, University of Malta, Malta. ${ }^{ \pm}$Educational Management Graduate Student, Lebanese International University, Lebanon. Hundergraduate Student, Faculty of Tourism and Hospitality Management, Lebanese University, Lebanon.
} 
Nowadays, one of the main elements of sustainable development is to balance our environment and economic and social needs, allowing future prosperity and future generations (UNCED 1992). This includes economic equality and ecofriendly systems. Sustainability of transportation has been used for quite some time now, and the means of transportation are safe and have a profound influence on the environment.

It is essential to know that sustainable transportation uses renewable energy rather than fossil fuels that can harm the environment (Gilbert 2005, Conserve Energy and Future 2020). Velazquez et al. (2015) also discusses this.

This research seeks to review the sustainability of transportation in Lebanon in its broadest scope (cf. Sraj 2015, Velazquez et al. 2015). This will be done by exploring the problems and solutions that can improve the transportation sector. Due to the lack of sustainable transportation, this research could help fill gaps to improve Lebanon's transportation sector (see World Bank 1996, Conserve Energy and Future 2020).

The objectives of this study is to investigate and analyze the factors of the problem of transportation in Lebanon and make specific suggestions to enhance the role of transportation in promoting sustainable development, mainly public transportation (see UNCED 1992, Azar 2021).

\section{Literature Review}

Throughout the literature, there is a consensus, that transportation activity must be sustainable on three levels - economic, environmental and social. (February 16, 2004, the Minister responsible for Transport Canada laid before Parliament the document Sustainable Development Strategy 2004-2006). Research in this field was also conducted by Altinay and Paraskevas (2008). The IEREK conference held in Palermo, Sicily (from Oct 25, to 27, 2017) specifies issues pertaining to Architecture and Green Urbanism, in Italy and Netherlands, while the UNCED (1992) for similar issues in Brazil.

The most widely accepted definitions of comprehensive sustainable transportation are the ones provided by the Organization for Economic Cooperation and Development (OECD 2000), the Centre for Sustainable Transportation and by the European Commission (WCED 1987, Gilbert 2005). According to the OECD, and from an environmental point of view, sustainable transportation is: "An environmentally sustainable transport system is one that does not endanger public health or ecosystems and meets needs for access, consistent with maximizing the use of renewable resources and minimizing the use of non-renewable resources" (OECD 2000).

On the other hand, the Centre for Sustainable Transportation (or CST) defines sustainable transportation as a system, which offers citizens a safe and eco-friendly access while maintaining its affordability (Gilbert 2005). The CST also gives high importance for limiting the use of conventional energy sources all while reducing the amounts of land and noise pollution (Gilbert 2005). 


\section{Transportation and Tourism}

The transportation system affects the tourism sector, especially during the peak season; due to different modes in the transport system tourists use to reach the main destinations and touristic attractions. At the same time, workers, both directly and indirectly involved in tourism, are also using various transportation modes in order to reach their workplace and commute back home.

One of the most important indicators of the tourism sector in the Lebanese economy is represented by the number of jobs created by the tourism industry by which the direct contribution of travel and tourism was valued at USD 3.8 billion in 2018, accounting for 7\% of Lebanon's GDP (IDAL 1994).

Given the rather large positive impact Lebanon's tourism has on the local GDP, the country is in a dire need for a more sustainable, efficient, and effective local transportation system and means.

The heavy traffic caused during high tourism seasons causes heavy traffic on the local roads, making it burdensome for the citizens. This, however, opens room for the country's private sector and foreign direct investors to provide solutions for the current situation, transferring what we now call a problem into a business opportunity (IDAL 1994).

\section{Sustainable Transportation Indicator}

Sustainability indicators provide a basis for monitoring and measuring the extent to which the key sustainable transportation issues of a tourism destination are being met (see Table 1). The main three categories of sustainable transportation indicators are environmental, social and economic (UNWTO 2004).

Environmental Indicators include emissions, mode split, non-motorized transport and effective management of resources. The environmental indicators are the friendliest indicators in sustainability of transportation. This indicator helps to avoid air pollution and decreases the number of individual vehicle emissions, in addition, to the climate change issues and traffic (OECD 2001).

Economic Indicators include three kinds of indicators: transportation costs, traffic congestion, and commute speed/length of trip such as transportation costs, congestion and commute speeds (Chalak et al. 2015, Sraj 2015).

Social Indicators are represented by quality of life including noise pollution, cultural conditions, and health. These indicators help to increase the productivity and educational changes, family sizes, policy effectiveness, safety, personal security, public involvement, reliability, affordability and cultural preservation. (Chalak et al. 2015, Sraj 2015).

\section{Sustainable Transportation Strategies}

The most effective way to progress towards sustainability consists of implementing strategies to intensify the efficiency of the transportation system and decrease harmful impacts (Litman 2009). 
Table 1. Sustainable Transportation Indicators (see Gilbert 2005)

\begin{tabular}{|l|c|c|}
\hline Environmental & Economic & Social \\
\hline Emissions & Traffic congestion & Quality of Life \\
Mode Split & Commute Speed & (Noise pollution, \\
Non-Motorized Transport & Transportation costs & Cultural and health) \\
\hline
\end{tabular}

Sustainable transportation strategies include consumer demand management, operations management, pricing methods, vehicle technology enhancements, nonconventional sources of energy, and transportation planning (Figure 1). In the past, this was difficult to implement, however a new interest in actively pursuing these strategies has emerged (Litman 2009).

Conceiving urban transportation laws and policies develop a sustainable urban transport system through implementing laws and policies which identify the status of transport modes, transport financing sources and transport planning principles. Using more affordable public transportation will lead to less car usage, while encouraging public transport use will help reduce road congestion and will ensure transport access for all social groups (Azar 2021).

\section{Lebanese Transportation}

The current Lebanese transport system mainly relies on vehicles as a mode of transport, where private passenger cars share the highest number. In 2007, 80\% of the total of 1.55 million vehicles operating were private passenger cars. As for car ownership, it was three people for every car in 2002, but expected to increase by $1.5 \%$ each year. These passenger cars are characterized by being old, exceeding the age of 13 years as an average, and poorly maintained. Engine displacement (engine size) is considered to be another problem, where it exceeds 2 liters in 60\% of the cars (see Conserve Energy and Future 2020).

Additionally, the Land transportation faces a lot of challenges, specifically the infrastructure and system management which requires attention in order to deliver an acceptable level of service with attention to environmental, health and safety impacts (ESCWA 2009).

Figure 1. Strategies for Sustainable Transportation (Velazquez et al. 2015)

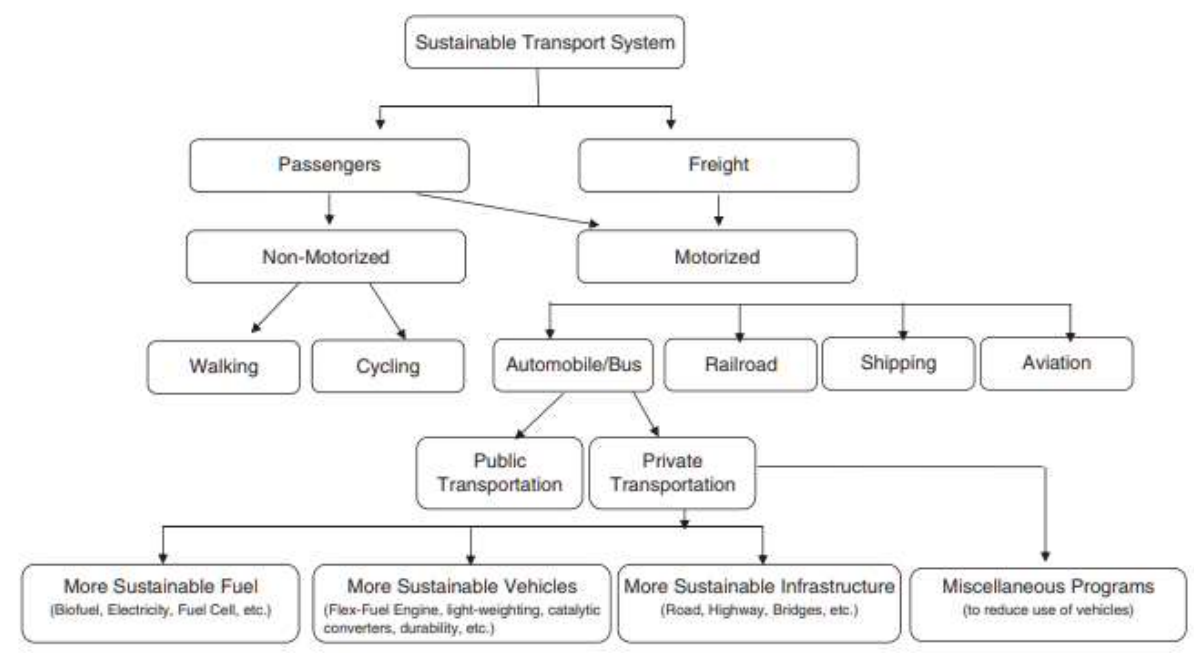


Lebanon's major transport- related problem is the bad status of its public transport sector (see Conserve Energy and Future 2020, Azar 2021). Regulations, implementation and monitoring processes are not efficient, with no specific entity fully responsible for the sector. A modern, well-organized, and operated public transport ensures a sustainable transportation sector, specially, since public transportation is one of the main modes to achieve sustainability in the sector (Conserve Energy and Future 2020). Effective deployment of the public transport does not only reduce various types of five pollutions, but also has lower expenses on both government and citizens (Conserve Energy and Future 2020).

Public transportation is a facility to grant citizens their social right of mobility, through following four basic objectives: Being accessible to all people, covering a certain geographical area, being safe and reliable, and affordable to all levels of society. The public transport sector in Lebanon, compared to international standards, is considered to have a low demand with only $30 \%$ coverage of the total transport demand (see Conserve Energy and Future 2020).

If well managed, the sector will increase government revenue by 421 million $\mathrm{LBP} /$ month, rather than 105 million LBP/month. The public transport sector in Lebanon is made up of two main modes: shared taxi and buses. The shared taxi is the most common used model, made up of automobiles and minivans, operating randomly with semi-determined or pre-determined tracks. Another type of public transport is the private taxis, owned by companies and operating by phone call requests. The public sector covers around $20 \%$ of the total demand in the Greater Beirut Area (GBA). Before the civil war, the number of taxis was 10,000 (see Chalak, et al. 2015, Conserve Energy and Future 2020). However, in the 1990s, it increased to more than 30,000, exceeding the demand of the community (see Community Transportation Association 2011, Chalak et al. 2015). Over demand brought low revenue for the taxi drivers, preventing them from improving their vehicles, resulting in a large number of old and poorly maintained cars (Sraj 2015).

Taxis and Car Rental services in Lebanon are undeniably the best mode of transportation in comparison with the others. Some might even argue that taxis (cabs), including but not limited to the "Ubers", are the most preferred method of transportation for tourists as well as for locals themselves, especially among the youth. As for car rentals, the spike in fuel prices, coupled with the poor road conditions, and rather expensive car rental fares, make this less attractive as a mode of transport either for tourists or for locals.

Trains and Buses are among other options. Yet, for tourists in Lebanon is the use of buses or mini vans to travel from Beirut, where most tourists reside, to touristic areas in the northern and southern governorates of Lebanon. This is due to the absence of train (or tram) lines in the country, a method of transportation which was put on halt during the country's civil war (Travel Guide 2018). In the case of the trains, even though they were not in circulation for decades, the state still has employees on its payroll (Travel Guide 2018). 


\section{Methodology}

In order to better understand the Lebanese transportation sector, the researchers decided to conduct a qualitative method by conducting two questionnaires separately with the residents and visitors, in order to facilitate our data interpretation such that we could interpret the results better, besides an interview with an expert in Lebanese transportation. Our research design has followed Walker (1985), Strauss and Corbin (1990), and Merriam (1998).

Figure 2 explains the methodology behind the research design the researchers selected for this study since it includes inductive approaches, whereby providing $a$ posteriori hypotheses, or hypotheses would be generated after the qualitative data would be collected, as Saunders et al. (2019) suggest. Thus, the qualitative research design was selected chiefly because of data collection tools used.

The residents' questionnaire focuses on transportation methods in Lebanon such as car, bus, public transportation, taxi, bicycle, and so on. In addition, it includes the point of view of the residents, whether they agree/disagree about sustainability of transportation in Lebanon (Saunders et al. 2019). This part interrogates the opinion and behaviors about the main problems in the transportation sector, the residents suffering from public transportation, infrastructure and if we can improve such elements as sidewalks, pollution, lanes for bicycles, traffic or congestion delay (Azar 2021).

Moreover, we can use new sustainable ways in transportation like bicycling or walking, if there would be a good alternative strategy for transportation to limit the effects of the different problems, like reducing traffic, reducing pollution, less noise and better sightseeing (Saunders et al. 2019).

Furthermore, the visitors questionnaire focuses on the form of transportation used (rent car, bus, taxi...). The main problems (traffic, pollution, lousy infrastructure, high chance of accident, high cost) and the solutions (train station, fare card, public transportation management system, route infrastructure management...) to give the comfortable ideas to transporting visitors to the destination/tourists' sites are discussed (Saunders et al. 2019). Besides, the questionnaires and the interview with the owner of Go Taxi using a self-selection sample by distributing an online survey, due the COVID-19 and the difficult current period (Saunders et al. 2019).

\section{Research Questions}

As the purpose of the research questions were to properly address the current study objectives, purpose of this study is to explore and examine the issues involving the transportation problem in Lebanon while proposing specific recommendations to mainly improve the role of public transportation in promoting sustainable development in Lebanon (UNCED 1992, Conserve Energy and Future 2020).

Therefore, several questions have been addressed in this study, as those listed below:

Is the transportation in Lebanon considered sustainable? 
If not, what are the problems?

How can we avoid them?

What are the suitable recommendations?

Do the solutions suggested in this study lead to sustainability in the future?

Figure 2. Saunders' Research Onion to Explain the Research Design (Saunders et al. 2019) - Our Research Design Also Follows Leedy (1993)

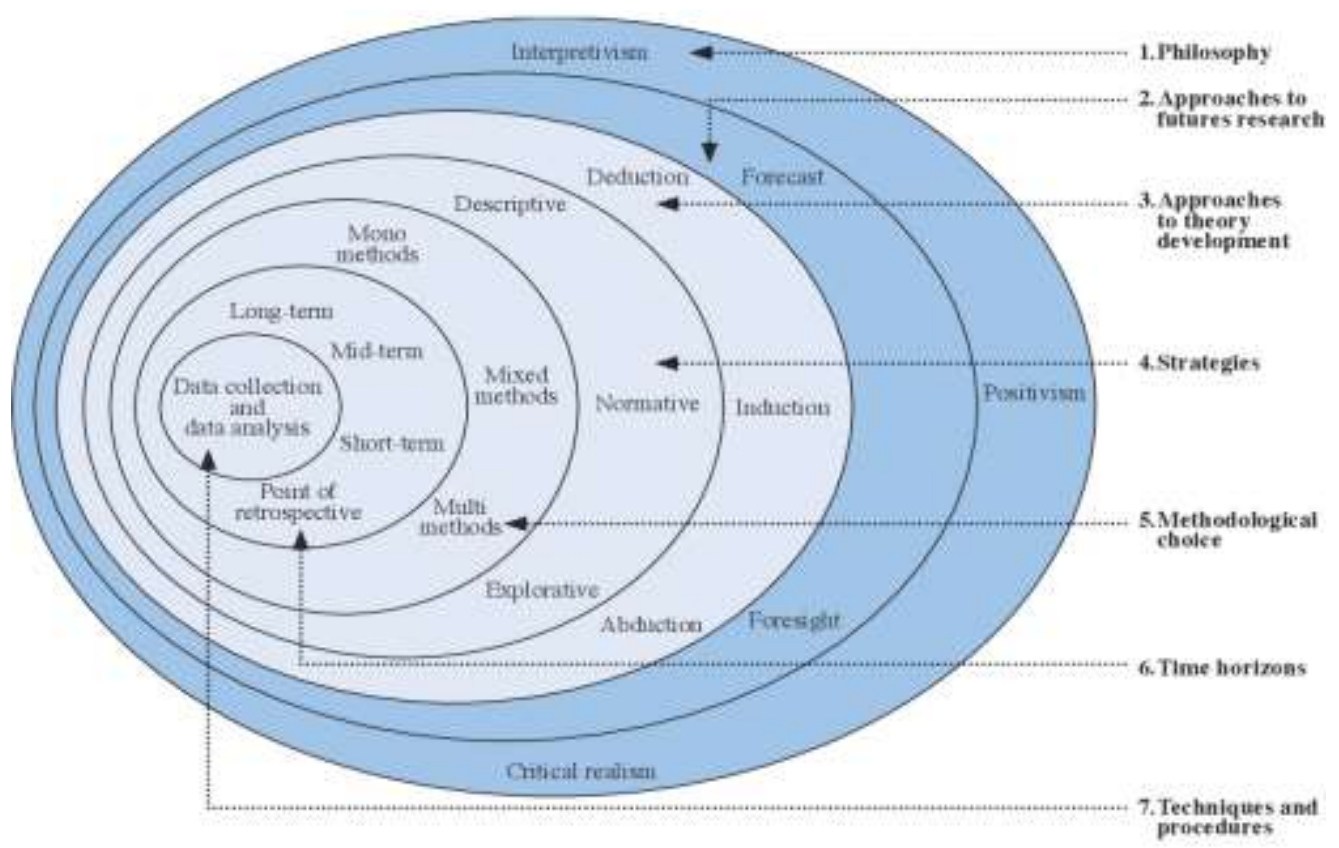

\section{Results}

The following section includes both the findings of the surveys and the interviews.

\section{Results and Interpretations from the Surveys}

Out of the 90 participants (visitors) who took part in the survey, $61 \%$ of them said that they use cabs, while $28 \%$ of them noted that they use services such as rent a car, whereas only $11 \%$ use the bus. This is shown in Figure 3. 
Figure 3. Graph Showing the Responses of the Tourists with respect to the Preferred Modes of Transportation

Preferred transportation (Visitors)

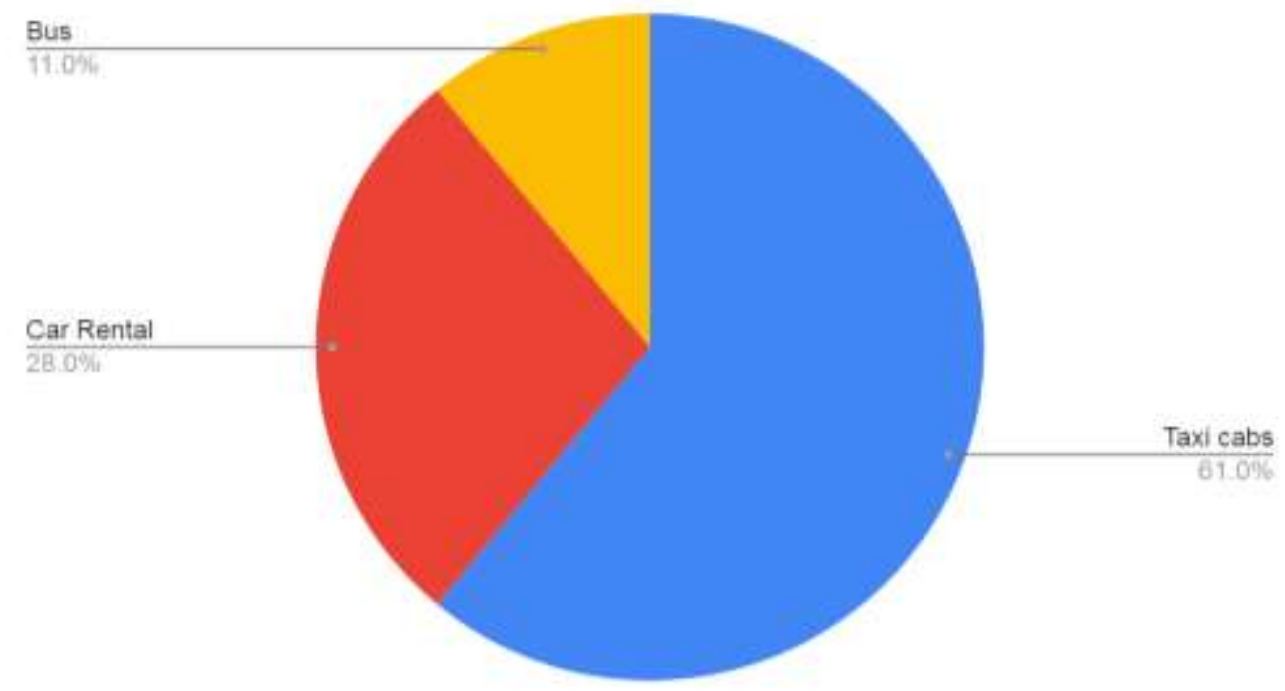

Figure 4. Graph Showing the Responses of the Locals with respect to the Preferred Modes of Transportation

Preferred transportation (residents)

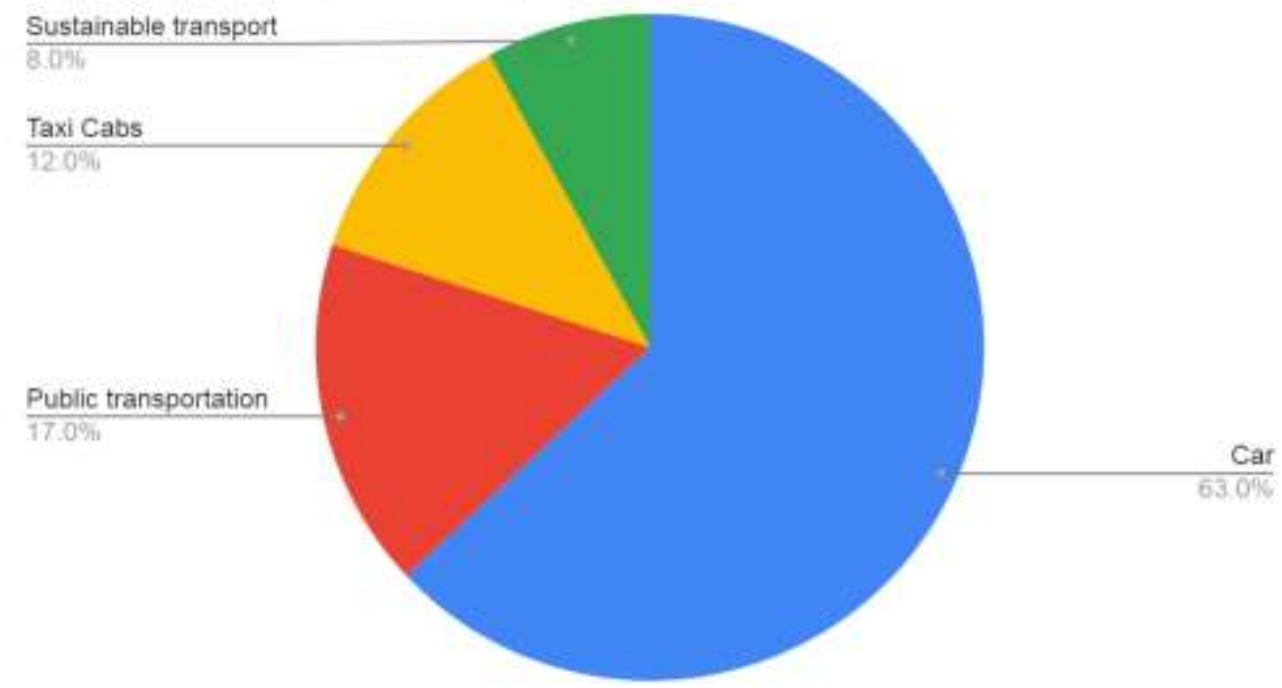


Figure 5. Graph Showing the Responses of both Locals' and Tourists' Satisfaction with the Infrastructure in terms of Site Accessibility

\section{the infrastructure is good and accessible enough for the site}

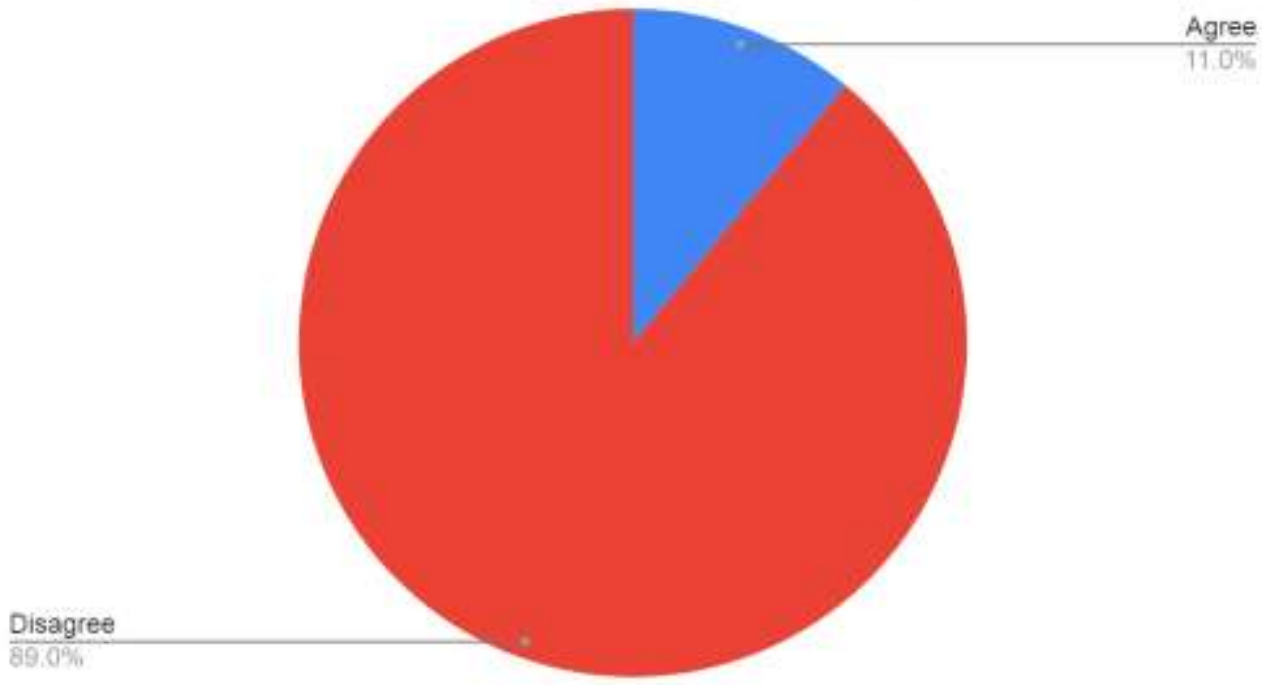

For the residents, it was noticed that $63 \%$ of them use a car, $17 \%$ use public transportation, $12 \%$ of them utilize taxi cabs, and only $8 \%$ of them rely on sustainable alternatives to cars, such as bikes. Figure 4 shows the corresponding pie chart (Azar 2021).

While the majority (89\%) of the respondents (comprising both tourists and locals) disagreed with the statement that 'the infrastructure is good and accessible enough for the site' and $11 \%$ of them have agreed. The corresponding pie chart is shown in Figure 5.

Since the majority disagreed, to the above statement, $83 \%$ of the respondents (so, perhaps, a similar number) noted that they are suffering from several problems in transportation: traffic problems, lousy infrastructure, pollution, accidents and highest cost, against $17 \%$ stating that they weren't. This is shown in Figure 6.

Yet, $45 \%$ of the tourists stated that they disliked to use public transportation in Lebanon. This is since they find that in Lebanon public transportation: is unsafe, expensive and time consuming. This could add to the reasons why some of the tourists hate public transport, reiterating the fact that the transportation costs are high, as shown in Figure 6.

While, over $78 \%$ of the sampled population (visitors) said that they were suffering from transportation problems, from traffic, pollution, and lousy infrastructure in Lebanon. This could also be included in the list of potential reasons why most tourists hate public transport in Lebanon.

Moreover, $72 \%$ of the sampled participants (visitors) agree to use public transportation from an area to another. Likewise, most of them also concurred on the importance of improving the public transportation system in Lebanon for decreasing congestion delay (Bosch et al. 2017). 
Figure 6. Graph Showing the Responses of both Locals' and Tourists' Suffering from Transportation Problems

\section{Are you suffering from transportation and traffic problems, lousy infrastructure, pollution, accidents and highest cost?}

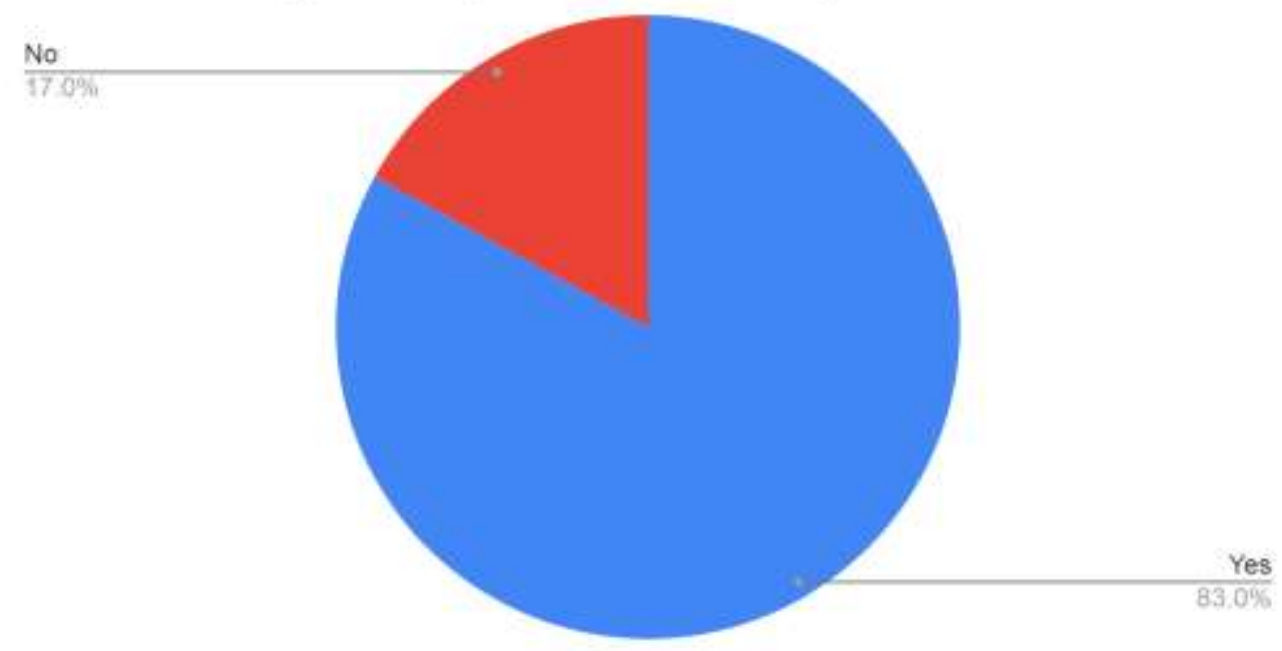

However, and as shown in Figure 7, currently, in Lebanon the percentage of the responses pertaining to the sustainability of transportation in this country is 91.5\% unsustainable, against $8.5 \%$ sustainable. Thus confirming that the majority of the respondents disagree on the fact that transportation in Lebanon is sustainable.

Figure 7. Sustainability of Transportation in Lebanon

12. In your opinion, do you consider the transportation in Lebanon as sustainable? 82 responses

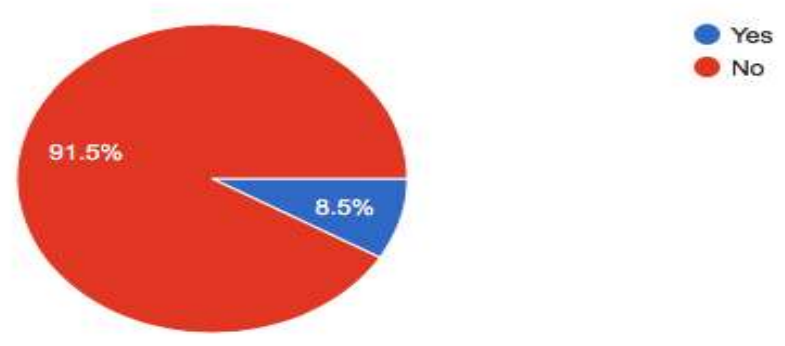

These alternative ways contribute to reducing traffic by $38.8 \%$, by $34.4 \%$ to avoid pollution and by $22.2 \%$ to have good health/wellness reasons. Thus, most of the participants (both visitors and residents) believe that in Lebanon, transportation is not sustainable, even though there are alternative ways of transportation like bicycling and walking. Lastly, 63\% of the sampled residents also suggest creating a train station, followed by at least $27 \%$ of the responses recommend also about innovating the public transportation management system Finally, a small number (at most 10\%) of the respondents suggest that it was needed to manage the Lebanese road network/infrastructure, as presented in Figure 8. 


\section{Transportation Types}

In terms of transportation types, as the tourists preferred taxis over locals who at an equivalent percentage use their cars. Naturally, these statistics make sense as tourists rarely come into Lebanon by their own cars, so the statistics are inverted as percent respondents using cars, or cabs are reversed for tourists with respect to locals.

Figure 8. Recommendations of Improvement for Transportation in in Lebanon

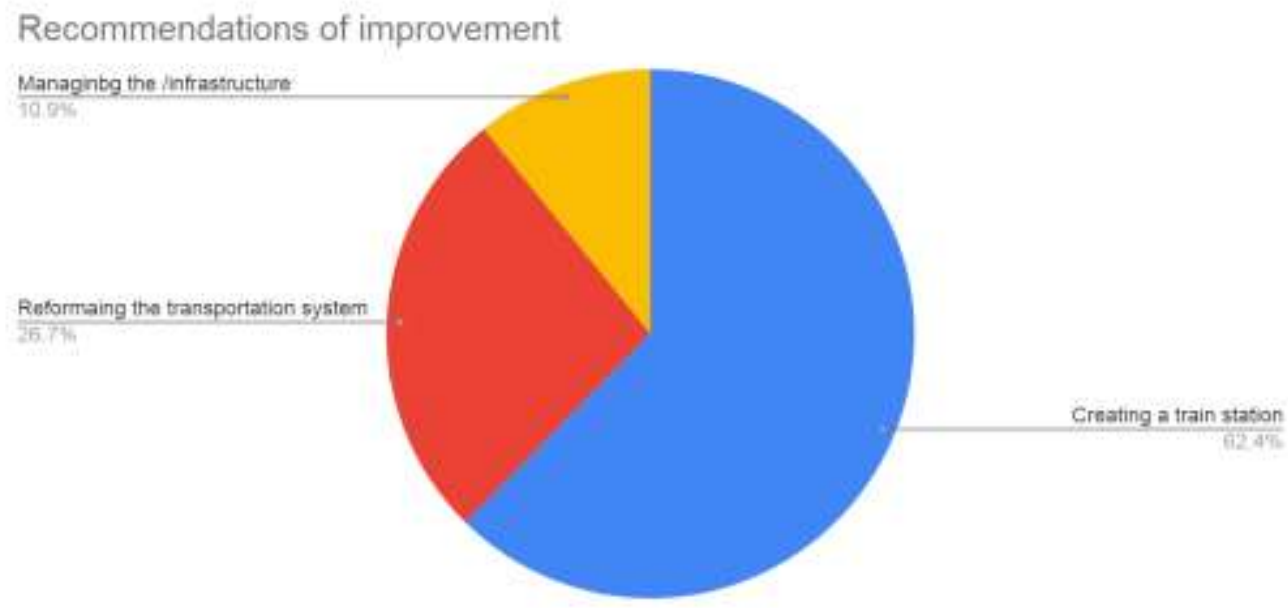

\section{Infrastructure}

As the majority of the addressed participants were dissatisfied with the infrastructure, this is one of the reasons nearly half of the addressed visitors refused to use public transportation in Lebanon, as they deemed it being unsafe, expensive and ineffective. This also caused a large part of the addressed visitors to suffer from those transportation problems, from traffic, pollution, as a result of this lousy infrastructure in Lebanon.

While a similar number of locals would use public transportation while commuting to different areas, the majority of the targeted subjects concurred that arranging this infrastructure would not only improve the transportation situation in the country, it would also greatly reduce traffic situations.

\section{Problems and Public Transportation}

In terms of transportation problems cited by visitors' by both locals and visitors traffic problems pollution and lousy infrastructure.

\section{Sustainable and Alternative Transportation}

A large number of participants (visitors and residents) do not consider the transportation in Lebanon as sustainable. There are alternative ways of sustainable transportation like bicycling and walking. Both participants, residents and visitors approve for alternative transportation and it could be a good way for transportation (Conserve Energy and Future 2020).

These alternative forms of transportation will be beneficial in the long run since these modes of transport will decrease traffic by $38.8 \%$, avoid pollution by 
$34.4 \%$, and provide an increase in good health/wellness reasons $22.2 \%$ (Bosch et al. 2017).

\section{Participants' Recommendations}

Finally, as most tourists and locals recommended, reintroducing train stations, enhancing the infrastructure management systems, and having a safety and vehicle control system, including the reforming of the Lebanese road infrastructure.

\section{Interview Results}

Our interview (the interviewee's name was kept confidential for ethical purposes) was very beneficial to the research since it gave a professional insight on the transportation system current situation in Lebanon. According to the interviewee, 60 to 200 visitors per day using car rental services or taxi cabs, and rarely use public transportation in Lebanon from the airport. Public transportation is not often accessible to all destinations/sites and is time consuming and inefficient.

Besides, they transport the visitors by a new model of buses or cars with high conditions, drivers, good communication, and fast service and provide the visitors with all the information needed, such as flight details. The cost of each service depends on the destination, driving time, rental car per day. The transportation system in Lebanon could not be so sheep because they have many problems.

The interviewee mentioned that transportation in Lebanon has many problems: inadequate infrastructure, unacceptable routes, traffic, insufficient sightseeing, pollution, noise, takes time, costly, inadequate public transportation management system, inadequate programs, the absence of the responsibility by institutions concerned, and substandard planning. A comparison could have been discussed by Wood (1999) in terms of transportation programs.

It can be improved by having a good infrastructure management system, train stations and public transportation buses for reducing traffic and less pollution and reducing public transportation problems. Yet, Public transportation can be improved by giving priority to the public sector. This sector should have control of public transport operations, improve public transport planning with safety and security regulations, provide accurate information to the customers, and provide a fare card.

The transportation sector is vital in the tourism sector. It is the principal means to carry passengers and is the first service the visitors need in their journey. The development of transportation to speed up the development of tourism realized by renewing vehicles, infrastructure, and using new technologies in this sector, provide strategies and new projects like new airports or new train stations.

The interviewee makes aware of the alternative transportation ways as not accessible for all the destinations, and it is challenging to transport visitors, like walking and bicycling, it takes time and is not easy to apply. Nevertheless, alternative transportation may be a good way for residents and would be friendlier for the environment, while reducing transportation problems. 
We can recommend many solutions to transportation in order to be sustainable in Lebanon, by improving public transportation, providing a good management system, planning, good infrastructure management, using a good alternative way to reduce pollution and less cost.

\section{Discussion}

Based on the results of questionnaires and interviews, the majority of participants, residents, and visitors pointed out that traffic and lousy infrastructure are major issues, affecting not only the transportation, but also other sectors and life in Lebanon.

Firstly, the lousy infrastructure, absence of public transportation due to the absence of a strategic plan, a lack of cooperation between the stakeholders involved in transportation in the tourism sector, and in different fields.

Secondly, the issue of traffic and massive vehicles, factors considering the quality of life such as noise pollution and aesthetic conditions and the factor air pollution are the least factors people are concerned about.

The transportation in Lebanon lacks sustainability due to various problems; lack of good quality in infrastructure, lack of equability to infrastructure, no projects, no investments, and no help from the country itself.

Confronting the interviewees with the possible potential and perspectives for sustainable transportation in Lebanon, related to tourism, all interviewed stakeholders see a considerable potential in sustainable transportation in tourism (Conserve Energy and Future 2020).

Unfortunately, we do not contain alternative ways to help make transportations sustainable that could help through restrictions such as: each household should have at most 3 to 4 cars. We lack laws that are enforced by the authorities, or strategies aiming at attaining sustainability. In other words, the absence of sustainability would not help those in the future generations in order to attain improved transportation networks and a better quality lifestyle.

Firstly, it's important to note that supporting the public transportation management system in Lebanon helps to optimize and automate the flow of public transport vehicles.

Secondly, providing a route information system and an electronic timetable that informs all consumers of the conditions on the route and the options available to them can help ease transportation.

Thirdly, enforcing safety and vehicle control systems can help to prevent accidents by alerting and assisting with dangerous road conditions.

Fourthly, having a single fare card which allows consumers to travel anywhere in the city, using all available public transportation options with one rechargeable fare card would help in lowering the cost of transportation while providing various options.

Furthermore, pollution could be significantly decreased if consumers were provided a smart transport system, which can promote and facilitate the use of public transportation methods all while providing real-time schedule and delays. 
This can reduce the use of private cars and encourage an eco-friendly or alternative way to reach your destination.

Additionally, safety should be regarded as of extreme importance in the public transportation system. It can be improved through monitoring and supervision which can help identify and increase the response time to emergencies, or terror attacks. In later stages, it can also reduce the accident rates across a city.

Finally, developing a smart parking solution with the right infrastructure, sensors, security cameras, and internet connectivity, can resolve the problem of overloaded parking spaces. Municipalities can share data on available parking, and consumers can access this data via mobile apps and web interfaces, all of which will lead us to a mobility in the marketplace, which is an open data regarding transportation and movement in the city. The smart parking solution creates a business opportunity for mobile app developers to create an app that can help consumers travel and consume transport services across the city.

\section{Conclusion}

After analyzing the data and obtaining results, it has come to notice that Lebanon had various transportation problems; however, only two were mostly voted on by visitors and residents; traffic and lousy infrastructure. Unfortunately, Lebanon is not a sustainable country in the transportation sector. After receiving numerous recommendations and interviews, it has shown that having sustainable transportation would help reduce transformational problems and provide us with a promising future (Conserve Energy and Future 2020).

Several recommendations suggested from the data collection, helping transportation to be sustainable for the future, are presented below:

- Creating a route information system and electronic timetable which informs travelers and locals of the conditions on the route and which public transport options are available would help to enhance public transportation.

- Enforce safety and vehicle control systems to prevent accidents by alerting and assisting with dangerous road conditions.

- Providing a rechargeable single fare card which allows consumers to travel anywhere in the city using all available public transport options. This would help in lowering pollution and increasing the beautiful sightseeing all while decreasing the cost.

- Bike sharing and carpooling applications and systems could create an ecofriendly transportation system to help better preserve the environment.

- Develop a smart parking solution with the right infrastructure, sensors, security cameras, and internet connectivity in cities which can reduce the time taken to park in busy urban areas. 


\section{References}

Altinay L, Paraskevas A (2008) Planning research in hospitality and tourism. New York: Routledge.

Azar G (2021, March 3) Public transport fares hiked in Lebanon amid mounting economic hardships. L'Orient Today.

Bosch P, Jongeneel S, Rovers V, Neumann HM, Airaksinen M, Huovila A (2017) CITYkeys indicators for smart city projects and smart cities. s.l.: European Commission.

Bougdah H, Versaci A, Sotoca A, Trapani F, Migliore M, Clark N (Eds.) (2017) Urban and transit planning conferences. Architecture and Green Urbanism. Italy and Netherlands: Springer.

Chalak A, Al-Naghi H, Irani A, Abou-Zeid M (2015) Commuters' behavior towards upgraded bus services in greater Beirut: implications for greenhouse gas emissions, social welfare and transport policy. Working Paper \#27. Issam Fares Institute for Public Policy and International Affairs American University of Beirut.

Community Transportation Association (2011) Chart of transportation reduced fare and free fare programs to serve low-wage earners. Community Transportation Association.

Conserve Energy and Future (2020) What is sustainable transportation? Conserve Energy and Future.

Gilbert R (2005) Defining sustainable transportation. The Centre for Sustainable Transportation.

Investment Development Authority of Lebanon - IDAL (1994) Invest Lebanon book: infrastructure and logistics. IDAL.

Leedy PD (1993) Practical research: planning and design. $5^{\text {th }}$ Edition. New York: MacMillan Publishing Company.

Litman T (2009) Transportation cost and benefit analysis: techniques, estimates and implications. $2^{\text {nd }}$ Edition. Victoria Transport Policy Institute.

Mammadov R (2012) The importance of transportation in tourism sector. In the Seventh Silk Road International Conference "Challenges and Opportunities of Sustainable Economic Development in Eurasian Countries". May 24-26.

Merriam S (1998) Qualitative research and case study: applications in education. San Francisco: Jossey-Bass Publishers.

Organisation for Economic Co-operation and Development - OECD (2011) Guidelines for multinational enterprises. OECD.

Saunders MNK, Lewis P, Thornhill A, Bristow A (2019) Research methods for business students. $8^{\text {th }}$ Edition. Pearson Education.

Sraj L-A (2015) Role of environmental non-government organizations in promoting sustainable transportation in Lebanon. Master Thesis. Lebanon: Faculty of Arts and Sciences, American University of Beirut.

Strauss A, Corbin JM (1990) Basics of qualitative research: grounded theory procedures and techniques. SAGE Publications Inc.

Travel Guide (2018) I explore, travel and leisure. Retrieved from: https://www.tra velandleisure.com/travel-guide. [Accessed 3 May 2021]

United Nations Conference on Environment and Development - UNCED (1992) Agenda 21: programme of action for sustainable development. Rio declaration on Environment and Development. Rio de Janeiro, Brazil: UNCED.

United Nations Economic and Social Commission for West Asia - ESCWA (2009) Annual report. ESCWA. 
Velazquez L, Munguia ME, Markus Will M, Zavala AG, Verdugo SP, Delakowitz B et al. (2015) Sustainable transportation strategies for decoupling road vehicle transport and carbon dioxide emissions. Management of Environmental Quality 26(3): 373-388.

Vince V (November 3, 2003) The global facilitation partnership for transportation and trade. World Trade Organization.

Walker R (1985) Applied qualitative research. Gower Pub Co.

Wood (1999) National wood in transportation program. United States: Department of Agriculture.

World Bank (1996) Sustainable transport: priorities for policy reform. Washington, USA: The World Bank.

World Commission on Environment and Development - WCED (1987) Our common future. Oxford/New York, UK/USA: Oxford University Press.

World Tourism Organization is the United Nations - UNWTO (2004) UNWTO tourism highlights. UNWTO.

World Tourism Organization is the United Nations - UNWTO (2017) Annual report. UNWTO. 